\title{
Preservação do inóculo de Plasmodiophora brassicae utilizando o método de congelamento
}

\author{
Juliana Cristina Sodário Cruz ${ }^{1}$, Nilton Luiz de Souza ${ }^{2}$, Carlos Roberto Padovani ${ }^{3}$, Edson Luiz Furtado ${ }^{2}$
}

\begin{abstract}
${ }^{1}$ APTA Pólo Centro Oeste, Rodovia SP 304, Km 304, CP 66, CEP 17201-970, Jaú, SP; ${ }^{2}$ Departamento de Produção Vegetal, Faculdade de Ciências Agronômicas, UNESP, CP 237, CEP 18603-970, Botucatu, SP, Bolsista CNPq; ${ }^{3}$ Departamento de Bioestatística, Instituto de Biociências, UNESP, CEP 18618-600, Botucatu, SP. Parte da Tese de Doutorado do primeiro autor.

Autor para correspondência: Juliana Cristina Sodário Cruz cruzjcs@apta.sp.gov.br
\end{abstract}

Data de chegada: 19/03/2007. Aceito para publicação em: 13/12/2007

1545

\section{RESUMO}

Cruz, J.C.S.; Souza, N.L.; Padovani, C.R.; Furtado, E.L. Preservação do inóculo de Plasmodiophora brassicae utilizando o método de congelamento. Summa Phytopathologica, v.35, n.1, p.57-5 9, 2009

A preservação das estruturas de resistência de Plasmodiophora brassicae, em condições laboratoriais, é dificultada pelo fato de se tratar de um parasita obrigatório. O método de congelamento, utilizando freezer, comum foi testado com o objetivo de viabilizar a sobrevivência e a preservação de suas características infectivas. Raízes de diferentes brássicas, naturalmente infectadas por $P$. brassicae, contendo sintomas típicos de hérnia, de uma mesma propriedade localizada no município de Pardinho, Estado de São Paulo, foram coletadas em diferentes épocas e imediatamente congeladas, em freezer, a aproximadamente $-20^{\circ} \mathrm{C}$. Os tratamentos foram divididos da seguinte maneira: T1: hérnias congeladas por 389 dias (rúcula); T2: hérnias congeladas por 242 dias (brócolis); T3: hérnias congeladas por 21 dias (couve chinesa) e T4: testemunha (sem inóculo). Os testes de patogenicidade, após diferentes períodos de armazenamento, foram realizados em condições de casa de vegetação $\left(25 \pm 2^{\circ} \mathrm{C}\right)$. Cada planta de uma variedade suscetível de couve-chinesa (Pak choi) foi inoculada com $2 \mathrm{~mL}$ da suspensão de esporos de cada tratamento, na concentração de $10^{7}$ esporos. $\mathrm{mL}^{-1}$. Cada tratamento contou com seis repetições distribuídas em blocos ao acaso. Passadas cinco semanas após a inoculação, as raízes das plantas foram lavadas e avaliadas. Houve diferença significativa entre os tratamentos. Os materiais congelados, entre 21 a 242 dias preservaram suas características infectivas, mostrando que o método de congelamento em freezer, nesse período, pode ser uma boa opção para a preservação das estruturas de resistência deste patógeno.

Palavras-chave adicionais: Hérnia das crucíferas, patógeno de solo, patogenicidade

\section{ABSTRACT}

Cruz, J.C.S.; Souza, N.L.; Padovani, C.R.; Furtado, E.L. Preservation of Plasmodiophora brassicae inoculum using the freezing method. Summa Phytopathologica, v.35, n.1, p.57-59, 2009

The preservation of Plasmodiophora brassicae resistance structures under laboratory conditions is difficult since this is an obligate parasite. The freezing method using an ordinary household freezer was tested to ensure the pathogen's survival and the preservation of its infective traits. Roots of different brassica species naturally infected by $P$. brassicae, showing typical clubroot symptoms, sampled in the same farm, located in the Pardinho County, State of São Paulo, were collected during different seasons and were immediately frozen at approximately $20^{\circ} \mathrm{C}$. The treatments were divided as follows: T1: clubroots frozen for 389 days (arugula); T2: clubroots frozen for 242 days (broccoli); T3: clubroots frozen for 21 days (Chinese cabbage), and T4: control (without inoculum). The pathogenicity tests were conducted under greenhouse conditions $\left(25 \pm 2^{\circ} \mathrm{C}\right)$. Each plant of the susceptible variety of Chinese cabbage (Pak choi) was inoculated with $2 \mathrm{~mL}$ of a spore suspension of each treatment at a concentration of $10^{7}$ spores. $\mathrm{mL}^{-1}$. Each treatment consisted of six replicates distributed in random blocks. The roots of plants were washed and evaluated five weeks after inoculation. There were significant differences between treatments. The frozen materials preserved their infective traits over a period of 21 to 242 days, demonstrating that the freezing method could be an option to preserve the resistance structures of this pathogen.

Keywords: Clubroot, soilborne pathogen, pathogenicity

A utilização de cultivares resistentes é a alternativa mais eficiente para o controle de Plasmodiophora brassicae, patógeno responsável pela doença conhecida como Hérnia das Crucíferas. Essa doença causa grandes prejuízos em diversas áreas cultivadas, principalmente em regiões de clima temperado. Os danos estão relacionados à formação de hérnias radiculares, decorrente da infecção, que acaba por impedir a absorção de água e nutrientes pela planta.

Alguns trabalhos relatam que a patogenicidade de $P$. brassicae não é muito prejudicada quando suas estruturas de resistência (cistos) são expostas a altas temperaturas, seja através da solarização (6), durante o processo de compostagem (3) ou em testes laboratoriais (9). Entretanto, apesar de ser um patógeno que se desenvolve bem em climas frios, pouco se sabe sobre seu o comportamento após longos períodos de exposição a baixas temperaturas.

Por se tratar de um patógeno biotrófico, sua manipulação em laboratório é dificultada, embora alguns raros trabalhos relatem a possibilidade de seu desenvolvimento em condições laboratoriais (2). Isto permite a observação e melhor entendimento da sobrevivência de suas estruturas de resistência, que geralmente são mantidas em hospedeiros (in vivo), em programas de melhoramento vegetal. 
Tabela 1. Severidade de Plasmodiophora brassicae em Brassica rapa spp. pekinensis, cv. Pak choi, preservado em diferentes períodos (dias), pelo método de congelamento em freezer.

\begin{tabular}{lcccc}
\hline Dias de congelamento & 389 & 242 & 21 & Testemunha \\
\hline Severidade da doença $^{2}$ & $0,0 \pm 0,5 \mathrm{a}^{1}$ & $3,0 \pm 1,0 \mathrm{~b}$ & $3,5 \pm 1,5 \mathrm{~b}$ & $0,0 \pm 0,0 \mathrm{a}$ \\
\hline
\end{tabular}

${ }^{1}$ Medianas seguidas pela mesma letra não diferem entre si segundo teste não-paramétrico de Kruskal-Wallis $(\mathrm{P}<0,001)$;

${ }^{2}$ Segundo scala visual de notas 0 a $4(0=0 \%, 1=25 \%, 2=50 \%, 3=75 \%$ e $4=100 \%)$.

Uma das grandes dificuldades enfrentadas por fitopatologistas e melhoristas de brássicas, principalmente visando resistência de plantas a $P$. brassicae, é a obtenção e armazenamento de inóculo do patógeno em condições ambientais tropicais brasileiras, que nem sempre permitem o desenvolvimento da doença.

O ciclo de vida de $P$. brassicae é dividido em fase primária e secundária. Na fase primária, estruturas de resistência do patógeno penetram nas raízes capilares transformando-se em plasmódios contendo zooporângios compostos por quatro a oito zoósporos. Esses zoósporos podem ser liberados pelos poros do hospedeiro e alguns se fundem, formando zigotos que podem causar novas infecções. Na fase secundária, os plasmódios produzidos nas células do hospedeiro invadem as células adjacentes, crescendo e se dividindo, causando hipertrofia e hiperplasia das células e conseqüentemente a formação de hérnias. Plasmódios maduros produzem as estruturas de resistência que depois da degradação do sistema radicular, são liberados no solo reiniciando todo o ciclo (1).

Em virtude da complexidade do ciclo de vida do patógeno e por se tratar de um parasita obrigatório, uma alternativa prática e viável de preservá-lo seria o armazenamento de raízes de plantas com hérnias contendo estruturas de resistência, sob condições especiais de armazenamento, como o congelamento em “freezer”, por apresentar maior praticidade e por ter sido eficiente na preservação de outros fitopatógenos $(4,5)$.

Diante disso, com o objetivo de determinar o período ideal de preservação das estruturas de resistência de $P$. brassicae, utilizando o método de congelamento, mudas de couve chinesa (Brassica rapa spp. pekinensis), de uma cultivar suscetível ao patógeno (Pak choi), com quatro semanas de semeadura, foram transplantadas para vasos contendo solo esterilizado e mantidos em condições controladas de casa de vegetação $\left( \pm 25^{\circ} \mathrm{C}\right)$, nas dependências do Departamento de Produção Vegetal/Defesa Fitossanitária da FCA-UNESP, Botucatu (SP).

O patógeno e suas estruturas de resistência foram obtidos de diferentes hospedeiros, naturalmente infectados, de uma mesma propriedade no município de Pardinho (SP), porém coletados em diferentes épocas. No teste de severidade, após cessado os diferentes períodos de preservação, foram utilizados os três materiais coletados com o patógeno (inóculo) submetidos a diferentes períodos de preservação em “freezer” $\left(-20^{\circ} \mathrm{C}\right)$ comum, os quais consistiram em tratamentos a saber: T1: raízes de rúcula com hérnias congeladas por 389 dias; T2: raízes de brócolis com hérnias congeladas por 242 dias; T3: raízes de couve chinesa com hérnias congeladas por 21 dias e T4: testemunha (sem inóculo).

As raízes contendo as hérnias foram trituradas em liquidificador por um minuto com água destilada. Entre a trituração dos diferentes isolados, o copo do liquidificador foi desinfestado superficialmente através das seguintes etapas: a) lavagem em água corrente com detergente comum; b) 1 minuto em solução de álcool a 70\%; c) 1 minuto em solução de hipoclorito de sódio a 2\%; d) enxaguado em água corrente.
As suspensões obtidas foram filtradas em camadas de gaze para a retirada de fragmentos de raízes e a concentração foi ajustada com o auxílio de hemacitômetro. Em seguida foram feitas inoculações no colo de cada planta com $2 \mathrm{~mL}$ da suspensão de esporos de $P$. brassicae na concentração de $10^{7}$ esporos. $\mathrm{mL}^{-1}$.

O delineamento experimental adotado foi de blocos ao acaso com quatro tratamentos e seis repetições. Cada parcela consistiu de um vaso contendo uma planta inoculada com o patógeno preservado nos diferentes períodos testados. Passadas cinco semanas da inoculação, as raízes das plantas foram removidas lavadas e avaliadas. Para tanto foi utilizada uma escala visual de notas variando de 0 a $4(0=0 \%, 1=25 \%, 2=50 \%, 3=75 \%$ e $4=100 \%)$, conforme a porcentagem da área radicular afetada (8). Os dados foram submetidos a análise de variância não - paramétrica de Kruskal-Wallis, complementada com o respectivo teste de comparações múltiplas (10).

Após 389 dias de congelamento, a infectividade de $P$. brassicae foi consideravelmente afetada, pois a formação de hérnias na cultivar suscetível de couve chinesa foi baixa. Este tratamento não diferiu da testemunha (sem inóculo). Entretanto, para os tratamentos onde as hérnias foram congeladas por 21 e 242 dias a infectividade foi preservada. Ambos os tratamentos não diferenciaram estatisticamente entre si, mas os dois diferiram da testemunha. Vale ressaltar que a severidade da doença quase chegou à nota máxima da escala utilizada, 4 - 100\% do sistema radicular afetado.

O resultado obtido discordou do de Miller relatado por Scott (7), que teve a viabilidade das estruturas de resistência deste patógeno diminuída quando estocadas a $-10^{\circ} \mathrm{C} \mathrm{e}-15^{\circ} \mathrm{C}$, por 90 dias, e também, pela possível redução da viabilidade dessas estruturas quando armazenadas a $-20^{\circ} \mathrm{C}$ por 56 dias.

Desta forma, o período de preservação ideal dos esporos de $P$. brassicae no método de congelamento deve ser até 242 dias para que suas propriedades infectivas não sejam afetadas, conforme dados da Tabela 1.

As características infectivas das populações do patógeno analisadas foram preservadas por até 242 dias. Este método quando comparado com o método de preservação do patógeno em plantas hospedeiras, que geralmente ocorre durante o período do ciclo de vida do hospedeiro (aproximadamente 70 dias), proporciona maior independência aos futuros trabalhos desenvolvidos, pois a qualquer momento o inóculo do patógeno pode ser buscado no freezer. Portanto o método de congelamento de raízes com hérnias em “freezer” $\left(-20^{\circ} \mathrm{C}\right)$, para a preservação de $P$. brassicae, mostrou-se prático e eficiente concordando com Garcia et al. (4).

O congelamento de raízes com hérnias infectadas por $P$. brassicae é uma boa opção para a conservação das estruturas de resistência do patógeno. No entanto, o período ideal de congelamento está entre 21 a 242 dias, para que suas características infectivas não sejam prejudicadas. O método mostrou-se prático e eficiente devido ao fato das características originais das populações do patógeno terem sido preservadas quando armazenadas a $-20^{\circ} \mathrm{C}$, durante o período citado. 


\section{REFERÊNCIAS BIBLIOGRÁFICAS}

1. Agrios, G.N. Plant pathology. 5.ed. San Diego: Academic Press, 2005. 922 p.

2. Asano, T.; Kodama, A.; Kageyama, K. Susceptibility of hairy rot lines of Brassica species to Plasmodiophora brassicae and in an in vitro subculture system. Journal of General Plant Pathology, Tokyo, v.72, n.2, p.85-91, 2006.

3. Fayolle, L.; Noble, R.; Coventry, E.; Aime, S.; Alabouvette, C. Eradication of Plasmodiophora brassicae during composting of wastes. Plant Pathology, Oxford, v. 55, n. 4, p. 553-558, 2006.

4. Garcia, E.O.; Casagrande, M.V.; Rago, A.M.; Massola-Júnior, N. S. Preservação de urediniósporos de Puccinia melanocephala, agente causal de ferrugem em cana-de-açúcar. Summa Phytopathologica, Botucatu, v. 33, n. 2, p.152-156, 2007.

5. Kirk, W.W. Tolerance of mycelium of different genotypes of Phytophthora infestans to freezing temperature for extended perio- ds. Phytopathology, St. Paul, v.93, n.11, p.1400-1406, 2003.

6. Myers, D.F.; Campell, R.N.; Greathead, A. Thermal inactivation of Plasmodiophora brassicae Woron. and its attempted control by solarization in the Salinas Valley of California. Crop Protection, London, v.2, n.3, p. 325-333, 1983.

7. Scott, E.S. Production and characterization of single-spore isolates of Plasmodiophora brassicae. Plant Pathology, Oxford, v.34, n.2, p. 287-292, 1985.

8. Takahashi, H.; Cebrian, I.T.; Souza, N.L. Inoculação de Plasmodiophora brassicae agente causal da "hérnia das crucíferas". Summa Phytopathologica, Botucatu, v. 31, supl., p. 16, 2005.

9. Takahashi, H.; Cebrian, I.T.; Souza, N.L. Inoculação e sensibilidade térmica de Plasmodiophora brassicae agente causal da "hérnia das crucíferas”. Fitopatologia Brasileira, Brasília, v.31, supl., p.138, 2006.

10. Zar, J.H. Biostatistical analysis, 4.ed. New Jersey: Prentice Hall, 1999. 663p. 